\title{
MEMODELKAN RASIO KETERSEDIAAN BERAS MENGGUNAKAN REGRESI DATA PANEL DINAMIS
}

\author{
Ni Putu Meiling Utami ${ }^{1 \S}$, I Wayan Sumarjaya ${ }^{2}$, I Gusti Ayu Made Srinadi ${ }^{3}$ \\ ${ }^{1}$ Program Studi Matematika, Fakultas MIPA - Universitas Udayana [Email: meilingutami@gmail.com] \\ ${ }^{2}$ Program Studi Matematika, Fakultas MIPA - Universitas Udayana [Email: sumarjaya@unud.ac.id] \\ ${ }^{3}$ Program Studi Matematika, Fakultas MIPA - Universitas Udayana [Email: srinadi@unud.ac.id] \\ ${ }^{\S}$ Corresponding Author
}

\begin{abstract}
The purpose of this research is to model and to determine the significant factor(s) that influence the ratio of rice availability at Province of East Java from 2007 to 2017 by applying dynamic panel data analysis. Independent variables of this research are land productivity, harvest area, and total population. The estimation method used are the first-difference GMM and system GMM. The best model to model the ratio of rice availability at Province of East Java is first-difference GMM and the independent variables which significant influence the ratio of rice availability at Province of East Java from 2007 to 2017 are lag ratio of rice availability, land productivity, harvest area, and total population.
\end{abstract}

Keywords: Ratio of Rice Availability, East Java, Dynamic Panel Data Regression

\section{PENDAHULUAN}

Beras merupakan bahan pangan pokok yang memegang peranan penting untuk mencapai ketahanan pangan yang stabil. Hal ini tecermin dari tingginya konsumsi terhadap beras dibandingkan bahan makanan lainnya. Berdasarkan UU Nomor 18 tahun 2012 tentang pangan, dijelaskan bahwa ketahanan pangan merupakan kondisi terpenuhinya pangan bagi negara sampai perseorangan tecermin dari tersedianya pangan yang cukup, baik jumlah maupun mutunya, aman, beragam, bergizi, merata dan terjangkau serta tidak bertentangan dengan agama, keyakinan, dan budaya masyarakat. Setiap tahunnya, kebutuhan akan beras terus meningkat seiring dengan peningkatan jumlah penduduk. Oleh karena itu, ketersediaan beras harus dapat dijamin oleh pemerintah sehingga kebutuhan beras dapat terpenuhi.

Indikator yang digunakan untuk mengetahui situasi pangan beras adalah rasio ketersediaan beras, yang digambarkan sebagai perbandingan jumlah produksi dengan jumlah konsumsi beras. Rasio tersebut menunjukkan apakah suatu daerah surplus atau defisit dalam produksi beras. Jawa Timur sebagai daerah lumbung padi Indonesia juga memiliki jumlah penduduk yang cukup besar. Pada tahun 2017, produksi beras Provinsi Jawa Timur mencapai 7,6 juta ton dengan jumlah konsumsi beras sebesar 4,3 juta ton. Dalam kondisi jumlah penduduk yang terus bertambah, Jawa Timur diharapkan tetap mampu mencukupi kebutuhan beras di wilayahnya sendiri bahkan berkontribusi kepada wilayah lain.

Sebagai bahan baku beras, penyediaan gabah dipengaruhi oleh luas panen dan produktivitas lahan. Produksi beras bergantung kepada penyediaan gabah dan rendemen beras. Penelitian mengenai faktor-faktor yang memengaruhi rasio ketersediaan beras telah dikalukan oleh Silalahi dkk. (2014). Hasil penelitian tersebut menunjukkan bahwa stok beras, luas areal panen padi, produktivitas lahan, jumlah konsumsi beras dan harga beras berpengaruh secara individu maupun secara keseluruhan terhadap rasio ketersediaan beras. di Sumatera Utara. Pada penelitian tersebut metode yang digunakan adalah analisis regresi data panel statis.

Mahbubi (2013) menyatakan bahwa sistem perberasan nasional bersifat dinamis. Metode data panel yang sesuai untuk memahami penyesuaian dinamis menggunakan metode 
regresi data panel dinamis. Hubungan dinamis dalam model dicirikan dengan menambahkan lag variabel dependen sebagai regresor (Baltagi, 2005). Penambahan lag variabel dependen pada model menyebabkan estimasi dengan pendekatan fixed effect maupun random effect akan menghasilkan penduga yang bias dan tidak konsisten. Untuk mengatasi masalah tersebut, model data panel dinamis dapat diestimasi dengan pendekatan generalized method of moments (GMM).

Penelitian menggunakan regresi data panel dinamis telah dilakukan oleh Nabilah dan Setiawan (2016). Penelitian tersebut menggunakan pendekatan first-difference GMM untuk memodelkan pertumbuhan ekonomi Indonesia. Hasil penelitian tersebut menunjukkan bahwa pertumbuhan ekonomi secara signifikan dipengaruhi oleh investasi luar negeri dan pengeluaran pemerintah. Penelitian menggunakan regresi data panel dinamis juga telah dilakukan oleh Hasriati (2016). Penelitian tersebut melibatkan efek spasial dengan pendekatan first-difference GMM dan system GMM dalam memodelkan konvergensi inflasi antarwilayah di Indonesia. Hasilnya adalah pendekatan dengan system GMM lebih efisien, dengan variabel yang berpengaruh terhadap konvergensi inflasi antarwilayah di Indonesia dengan melibatkan efek spasial adalah variabel suku bunga.

Pada penelitian ini penulis mengaplikasikan analisis regresi data panel dinamis dengan pendekatan first-difference GMM dan system GMM untuk memodelkan rasio ketersediaan beras di Provinsi Jawa Timur, serta untuk mengetahui pengaruh produktivitas lahan $\left(X_{1 i t}\right)$, luas panen padi $\left(X_{2 i t}\right)$, dan jumlah penduduk $\left(X_{3 i t}\right)$ terhadap rasio ketersediaan beras di Provinsi Jawa Timur pada tahun 2007-2017.

\section{METODE PENELITIAN}

\subsection{Model Penelitian}

Analisis regresi data panel adalah analisis regresi yang didasarkan pada data panel (Gujarati, 2004). Metode data panel yang digunakan untuk memahami penyesuaian dinamis adalah regresi data panel dinamis. Secara umum model regresi data panel dinamis adalah sebagai berikut:

$$
Y_{i t}=\delta Y_{i, t-1}+\sum_{k=1}^{K} \beta_{k} X_{k i t}+u_{i t}
$$

dengan $i=1,2, \ldots, N, \quad i=1,2, \ldots, T, \quad Y_{i t}$ menyatakan variabel terikat cross section ke- $i$ deret waktu ke- $t, Y_{i t-1}$ menyatakan lag $Y_{i t}, X_{i t}$ menyatakan variabel bebas unit cross section ke$i$ dan unit deret waktu ke- $t, \alpha$ menyatakan intersep, $\beta_{k}$ menyatakan lereng (slope) ke- $k$ variabel bebas, dan $u_{i t}$ menyatakan galat (error) regresi unit cross section $\mathrm{ke}-i$ dan unit time series ke- $t, \delta$ menyatakan skalar, $u_{i t}$ merupakan komponen galat satu arah. Pendekatan yang digunakan dalam mengestimasi model regresi data panel dinamis adalah first-difference GMM (FD-GMM) dan system GMM (SYS-GMM).

\section{1) First-Difference Generalized Method of Moments (FD-GMM)}

FD-GMM dikembangkan oleh Arellano dan Bond (1991). Pendekatan ini menghasilkan penduga takbias, konsisten, dan efisien. Berikut diberikan model data panel autoregresif AR(1) tanpa menyertakan variabel eksogen:

$$
Y_{i t}=\delta Y_{i, t-1}+u_{i t}
$$

Penduga $\delta$ konsisten satu langkah (one-step consistent estimator) diperoleh dengan menetapkan matriks pembobot $A_{N}$, yaitu (Arellano \& Bond, 1991):

$$
A_{N}=\left(N^{-1} \sum_{i=1}^{N} W_{i}^{T} G W_{i}\right)^{-1} .
$$

Diperoleh hasil estimasi GMM Arellano-Bond satu langkah (one-step estimator) sebagai berikut:

$$
\begin{gathered}
\hat{\delta}=\left[\left(N^{-1} \sum_{i=1}^{N} \Delta Y_{i, t-1}{ }^{T} W_{i}\right) A_{N}\right. \\
\left.\left(N^{-1} \sum_{i=1}^{N} W_{i}^{T} \Delta Y_{i}\right)\right]^{-1}\left[\left(N^{-1} \sum_{i=1}^{N} \Delta Y_{i, t-1}{ }^{T} W_{i}\right)\right. \\
\left.A_{N}\left(N^{-1} \sum_{i=1}^{N} W_{i}^{T} \Delta Y_{i}\right)\right]
\end{gathered}
$$

dengan $W_{i}$ merupakan matriks variabel instrumen. Variabel instrumen merupakan variabel yang tidak berkorelasi dengan galat, tetapi berkorelasi dengan variabel endogen eksplanatori. Penduga $\delta$ konsisten dua langkah (two-step consistent estimator) diperoleh dengan mengganti $A_{N}$ menggunakan matriks optimal sebagai berikut (Arellano \& Bond, 1991):

$$
\widehat{V}_{N}^{-1}=\left[N^{-1} \sum_{i=1}^{N} W_{i}^{T} \Delta \hat{v}_{i} \Delta \hat{v}_{i}^{T} W_{i}\right]^{-1}
$$

dengan $\Delta \hat{v}_{i}$ merupakan vektor residual yang diperoleh dari first-step consistent estimator.

\section{2) System Generalized Method of Moments (SYS-GMM)}

Blundell dan Bond (1998) menyatakan pentingnya pemanfaatan initial condition dalam menghasilkan penduga yang efisien dari model 
data panel dinamis ketika $T$ berukuran kecil. System GMM adalah metode yang digunakan untuk mengestimasi sistem persamaan dengan mengombinasikan momen kondisi first difference dan momen kondisi level.

\subsection{Teknik Analisis Data}

Adapun langkah-langkah analisis data yang dilakukan dalam penelitian ini adalah sebagai berikut:

1. Mengestimasi model regresi data panel dinamis dengan pendekatan FD-GMM dan SYS-GMM.

2. Melakukan uji spesifikasi model regresi data panel dinamis, yaitu uji Arellano-Bod dan uji Sargan.

3. Pemilihan model antara FD-GMM dan SYSGMM. Model dipilih berdasarkan hasil uji spesifikasi model regresi data panel dinamis. Jika kedua model memenuhi uji spesifikasi model regresi data panel dinamis, maka pemilihan model dapat dilakukan dengan melihat nilai galat baku (standard error) yang lebih kecil.

4. Melakukan uji signifikansi parameter pada model yang terpilih, yaitu uji serempak dan uji parsial.

5. Menginterpretasikan hasil yang diperoleh.

\section{HASIL PENELITIAN}

\subsection{Estimasi Model Regersi Data Panel Dinamis}

Pada tahap ini dilakukan pendugaan dalam model regresi data panel dinamis dengan penekatan first-difference GMM two step estimator dan system GMM two step estimator. Nilai intersep dan slope untuk setiap variabel independen dengan pendekatan FD-GMM dan SYS-GMM masing-masing ditunjukkan dalam Tabel 1 dan Tabel 2.

Tabel 1. Pendugaan Parameter dengan Pendekatan FD-GMM

\begin{tabular}{cccc}
\hline \hline Parameter & Koefisien & $\begin{array}{c}\text { Standard } \\
\text { Error }\end{array}$ & $\boldsymbol{p}_{\text {value }}$ \\
\hline \hline $\boldsymbol{\delta}$ & $-0,083249$ & 0,0031742 & 0,000 \\
\hline $\boldsymbol{\beta}_{\mathbf{1}}$ & 0,1892808 & 0,003978 & 0,000 \\
\hline $\boldsymbol{\beta}_{\mathbf{2}}$ & 0,000033 & $1,60 \times 10^{-7}$ & 0,000 \\
\hline $\boldsymbol{\beta}_{\mathbf{3}}$ & $-7,71 \times 10^{-7}$ & $1,27 \times 10^{-7}$ & 0,000 \\
\hline \hline Uji Wald & 123360,68 & & \\
\hline $\boldsymbol{p}_{\text {value }}$ & 0,000 & & \\
\hline \hline
\end{tabular}

Sumber: Data diolah, 2019
Tabel 2. Pendugaan Parameter dengan Pendekatan SYS-GMM

\begin{tabular}{cclc}
\hline \hline Parameter & Koefisien & $\begin{array}{c}\text { Standard } \\
\text { Error }\end{array}$ & $\boldsymbol{p}_{\text {value }}$ \\
\hline \hline $\boldsymbol{\delta}$ & $-0,0873195$ & 0,0053252 & 0,000 \\
\hline $\boldsymbol{\beta}_{\mathbf{1}}$ & 0,2286492 & 0,00459 & 0,000 \\
\hline $\boldsymbol{\beta}_{\mathbf{2}}$ & 0,0000281 & $1,72 \times 10^{-7}$ & 0,000 \\
\hline $\boldsymbol{\beta}_{\mathbf{3}}$ & $1,32 \times 10^{-6}$ & $3,01 \times 10^{-8}$ & 0,000 \\
\hline \hline Uji Wald & 2890000 & & \\
\hline $\boldsymbol{p}_{\text {value }}$ & 0.0000 & & \\
\hline \hline
\end{tabular}

Sumber: Data diolah, 2019

\subsection{Uji Spesifikasi Model Regresi data Panel Dinamis}

Uji spesifikasi model regresi data panel dilakukan dengan uji Arellano-Bond dan uji Sargan.

1) Uji Arellano-Bond ( $A B$-Test)

Uji Arellano-Bond dilakukan untuk mengetahui adanya korelasi antara satu komponen residual dengan komponen residual yang lain pada model FD-GMM dan SYS-GMM. Hipotesisnya sebagai berikut:

$H_{0}$ : Tidak terdapat autokorelasi pada sisaan orde ke- $i$,

$H_{1}$ : Terdapat autokorelasi pada sisaan orde ke- $i$.

Statistik uji Arellano-Bond dinyatakan pada persamaan berikut (Arellano \& Bond, 1991):

$$
m_{i}=\frac{\hat{v}_{i, t-m}^{T} \hat{v}_{*}}{\hat{v}^{\frac{1}{2}}}
$$

dengan $\hat{v}_{*}$ menyatakan estimasi komponen galat lag ke- $m$ dan $\hat{v}$ menyatakan komponen galat dari estimasi model. Apabila $\left|m_{i}\right|>Z_{\text {tabel }}$ atau $p_{\text {value }}<\alpha$, maka tolak $H_{0}$. Konsistensi GMM pada $m_{1}$ ditunjukkan dengan nilai statistik uji Arellano-Bond yang signifikan, sedangkan konsistensi GMM pada $m_{2}$ ditunjukkan dengan nilai statistik uji Arellano-Bond yang tidak signifikan. Hasil uji Arellano-Bond pada model FD-GMM dan SYS-GMM ditunjukkan dalam Tabel 3.

Tabel 3. Hasil Uji Arellano-Bond model FDGMM dan SYS-GMM

\begin{tabular}{ccc|cc}
\hline \hline \multicolumn{2}{c|}{ FD-GMM } & \multicolumn{2}{c}{ SYS-GMM } \\
\hline \hline \multicolumn{3}{c|}{ Nilai } & \multicolumn{2}{c}{ Nilai } \\
Statistik & $p_{\text {value }}$ & $\begin{array}{c}\text { Statistik } \\
\text { AB-Test }\end{array}$ & $p_{\text {value }}$ \\
& & AB-Test & \\
\hline \hline $\boldsymbol{m}_{\mathbf{1}}$ & $-3,4516$ & 0,0006 & $-3,5389$ & 0,0004 \\
\hline $\boldsymbol{m}_{\mathbf{2}}$ & 0,77811 & 0,4365 & 1,2364 & 0,2163 \\
\hline \hline
\end{tabular}

Sumber: Data diolah, 2019 
Hasil uji Arellano-Bond pada Tabel 3 menyatakan bahwa hasil uji $m_{1}$ pada model dengan pendekatan FD-GMM dan SYS-GMM diperoleh $m_{1}>\mathrm{Z}_{0,025}=1,96$ dan $p_{\text {value }\left(m_{1}\right)}<$ $\alpha=0,05$ yang berarti tolak $H_{0}$. Sedangkan hasil uji $m_{2}$ pada model dengan pendekatan FDGMM dan SYS-GMM diperoleh $m_{2}<\mathrm{Z}_{0,025}=$ 1,96 dan $p_{\text {value }\left(m_{2}\right)}>\alpha=0,05$ sehingga tidak cukup bukti untuk menolak $H_{0}$. Hal ini menunjukkan estimasi dengan pendekatan FDGMM dan SYS-GMM dapat dikatakan konsisten dan tidak terjadi autokerelasi.

\section{2) Uji Sargan}

Uji Sargan digunakan untuk mengetahui validitas penggunaan variabel instrumen yang jumlahnya melebihi parameter yang diestimasi (kondisi overidentifying restriction). Hipotesisnya sebagai berikut:

$H_{0}$ : Kondisi overidentifying restriction dalam estimasi model valid,

$H_{1}$ : Kondisi overidentifying restriction dalam estimasi model tidak valid.

Statistik uji Sargan dinyatakan dalam persamaan berikut (Baltagi, 2005):

$$
s=\hat{v}^{T} W\left(\sum_{i=1}^{N} W_{i}^{T} \hat{v}_{i} \hat{v}_{i}^{T} W_{i}\right)^{-1} W^{T} \hat{v}
$$

dengan $p$ merupakan jumlah kolom pada $W$. Keputusan $H_{0}$ ditolak apabila $\chi_{\text {hitung }}^{2}>\chi_{p-K-1}^{2}$ atau $p_{\text {value }}<\alpha$. Hasil uji Sargan pada model FD-GMM dan SYS-GMM ditunjukkan dalam Tabel 4.

Tabel 4. Hasil Uji Sargan model FD-GMM dan SYS-GMM

\begin{tabular}{cc|cc}
\hline \hline \multicolumn{2}{c|}{ FD-GMM } & \multicolumn{2}{c}{ SYS-GMM } \\
\hline \hline $\begin{array}{c}\text { Nilai Statistik } \\
\text { Uji Sargan }\end{array}$ & $p_{\text {value }}$ & $\begin{array}{c}\text { Nilai Statistik } \\
\text { Uji Sargan }\end{array}$ & $p_{\text {value }}$ \\
\hline \hline 37,69249 & 0,7374 & 32,98821 & 0,9859 \\
\hline \hline
\end{tabular}

Sumber: Data diolah, 2019

Hasil uji Sargan pada Tabel 4 menyatakan bahwa model dengan pendekatan FD-GMM dan SYS-GMM memiliki nilai $s<\chi_{\text {tabel }}^{2}=60,48$ dan $\quad p_{\text {value }}>\alpha=0,05$. Dengan demikian keputusan yang diambil untuk model dengan pendekatan FD-GMM dan SYS-GMM adalah tidak cukup bukti untuk menolak $H_{0}$, hal ini berarti kondisi overidentifying restriction dalam estimasi model valid.

\subsection{Pemilihan Model Regresi Data Panel Dinamis}

Hasil uji spesifikasi model regresi data panel dinamis menunjukkan bahwa pendekatan dengan FD-GMM dan SYS-GMM memenuhi uji spesifikasi model. Oleh karena itu, model dipilih berdasarkan nilai standard error yang lebih kecil. Berdasarkan Tabel 3 dan Tabel 4, nilai standard error dengan pendekatan FDGMM memberikan hasil yang lebih kecil. Hal ini menunjukkan bahwa pendekatan dengan FDGMM lebih efisien. Sehingga model yang layak untuk menggambarkan rasio ketersediaan beras di kabupatan/kota Provinsi Jawa Timur adalah model dengan pendekatan FD-GMM.

\subsection{Uji Signifikansi Parameter}

Pengujian signifikansi parameter dilakukan dalam dua tahap yaitu uji serempak dan uji parsial.

1) Uji Serempak

Uji serempak digunakan untuk mengetahui pengaruh semua variabel independen terhadap variabel dependen. Pada regresi data panel dinamis uji serempak dapat menggunakan uji Wald (Arellano \& Bond, 1991) dengan hipotesis sebagai berikut:

$H_{0}: \delta=\beta_{1}=\beta_{2}=\beta_{3}=0$,

$H_{1}$ : minimal ada satu $\delta, \beta_{k} \neq 0$, dengan $k=1,2,3$.

Statistik uji Wald dinyatakan pada persamaan berikut (Greene, 2012):

$$
W=\hat{\beta}^{T} V^{-1} \hat{\beta} \sim \chi_{K}^{2}
$$

dengan $V^{-1}$ menyatakan matriks kovarian asimtotik dari $\hat{\beta}$. Keputusan $H_{0}$ ditolak apabila nilai statistik uji $\mathrm{W}>\chi_{K}^{2}$ atau $p_{\text {value }}<\alpha$. Tabel 1 menunjukkan bahwa nilai Wald $>\chi_{\text {tabel }}^{2}=$ 9,49 dan $p_{\text {value }}<\alpha=0,05$, dengan demikian keputusan yang diambil ialah tolak $H_{0}$, hal ini berarti terdapat variabel independen pada model yang berpengaruh terhadap variabel dependen.

2) Uji Parsial

Uji parsial digunakan untuk mengetahui pengaruh masing-masing variabel independen terhadap variabel dependen. Hipotesis dalam pengujian ini adalah sebagai berikut:

$H_{0}: \delta, \beta_{k}=0$,

$H_{1}: \delta, \beta_{k} \neq 0$, dengan $k=1,2, \ldots, K$. 
Statistik uji parsial dinyatakan pada persamaan berikut:

$$
Z_{\text {hitung }}=\frac{\widehat{\beta}_{k}}{\operatorname{se}\left(\widehat{\beta}_{k}\right)}
$$

dengan $\hat{\beta}_{k}$ menyatakan koefisien regresi/slope ke- $k$ dan $\operatorname{se}\left(\hat{\beta}_{k}\right)$ menyatakan standar error dari slope ke- $k$. Keputusan $H_{0}$ ditolak apabila $\left|Z_{\text {hitung }}\right|>Z_{\text {tabel }}$ atau $p_{\text {value }}<\alpha$. Hasil uji parsial model regresi data panel dinamis dengan pendekatan FD-GMM dapat dilihat pada Tabel 1. Hasil tersebut menunjukkan bahwa lag variabel dependen dan seluruh variabel independen memiliki nilai $p_{\text {value }}<\alpha=0,05$, dengan demikian keputusan yang diambil ialah tolak $H_{0}$. Hal ini berarti lag variabel dependen, produktivitas lahan $\left(X_{1}\right)$, luas panen $\left(X_{2}\right)$, dan jumlah penduduk $\left(X_{3}\right)$ signifikan berpengaruh terhadap rasio ketersediaan beras di Provinsi Jawa Timur.

\subsection{Interpretasi Hasil}

Berdasarkan pendekatan dengan FD-GMM yang disajikan pada Tabel 1, diperoleh persamaan FD-GMM sebagai berikut:

$$
\begin{gathered}
Y_{i t}=-0,083249 Y_{i, t-1}+0,1892808 X_{1 i t} \\
+0,000033 X_{2 i t}-0,000000771 X_{3 i t}+u_{i t} \\
i=1,2, \ldots, 38 ; t=2007, \ldots, 2017 .
\end{gathered}
$$

Nilai $\delta=-0,083249$ menjelaskan bahwa jika terjadi peningkatan nilai rasio ketersediaan beras pada periode sebelumnya sebesar satu satuan maka akan menurunkan nilai rasio ketersediaan beras sebesar 0,083249 satuan. Nilai $\beta_{1}=0,1892808$ mengindikasikan rasio ketersediaan beras meningkat sebesar 0,1892808 satuan untuk setiap kenaikan 1 satuan produktivitas lahan. Nilai $\beta_{2}=0,000033$ bermakna jika luas panen meningkat sebesar 1 hektar (ha), maka dapat meningkatkan nilai rasio ketersediaan beras sebesar 0,000033 satuan. Nilai $\beta_{3}=-0,000000771$ bermakna setiap peningkatan jumlah penduduk sebanyak satu jiwa, maka dapat menurunkan nilai rasio ketersediaan beras sebesar 0,000000771 satuan.

\section{KESIMPULAN DAN SARAN}

Berdasarkan hasil dan pembahasan yang telah dipaparkan pada bab sebelumnya, kesimpulan dari penelitian ini adalah pendekatan dengan FD-GMM lebih efisien dibandingkan pendekatan dengan SYS-GMM dalam memodelkan rasio ketersedia-an beras di
Provinsi Jawa Timur. Faktor-faktor yang berpengaruh signifikan terhadap rasio ketersediaan beras di Provinsi Jawa Timur pada tahun 2007-2017 adalah nilai rasio ketersediaan beras pada periode sebelumnya, produktivitas lahan $\left(X_{1}\right)$, luas panen $\left(X_{2}\right)$, dan jumlah penduduk $\left(X_{3}\right)$.

Adapun saran yang diberikan untuk penelitian selanjutnya adalah melakukan pengujian efek spasial dalam model, sehingga dapat melakukan analisis regresi data panel dinamis spasial.

\section{DAFTAR PUSTAKA}

Arellano, M., \& Bond, S., 1991. Some Tests of Specification for Panel Data: Monte Carlo Evidence and an Application to Employment Equations. The Review of Economic Studies, 58(2), pp.277-297.

Baltagi, B. H. 2005., Econometric Analisys of Panel Data. 3rd ed. West Sussex: Wiley.

Blundell, R., \& Bond, S., 1998. Initial Conditions and Moment Restrictions in Dynamic Panel Data Models. Journal of Econometrics, 87, pp.115-143.

Greene, W. H., 2012. Econometric Analysis. 7th ed. New Jersey: Prentice Hall International.

Gujarati, D. N., 2004. Basic Economertrics. 4th ed. New York: The McGraw-Hill.

Hasriati, A., 2016. Pemodelan Konvergensi Inflasi Antar Wilayah di Indonesia dengan Pendekatan Spasial Dinamis Data Panel $A B-G M M$ dan Sys-GMM. Institut Teknologi Sepuluh Nopember.

Mahbubi, A., 2013. Model Dinamis Supply Chain Beras Berkelanjutan dalam Upaya Ketahanan Pangan Nasional. Jurnal Manajemen \& Agribisnis, 10(2), pp.81-89.

Nabilah, D., \& Setiawan, 2016. Pemodelan Pertumbuhan Ekonomi Indonesia Menggunakan Data Panel Dinamis dengan Pendekatan Generalized Method of Moment. Jurnal Sains dan Seni ITS, 5(2), pp.205-210.

Silalahi, D., Sitepu, R., \& Tarigan, G., 2014. Analisis Ketahanan Pangan Provinsi Sumatera Utara. Saintia Matematika, 2(3), pp.237-251.

Undang-Undang Republik Indonesia Nomor 18 Tahun 2012 Tentang Pangan. 